Hinden, E. (1962). Mumps followed by diabetes. Lancet, 1, 1381 King, R. C. (1962). Mumps followed by diabetes. Lancet, 2, 1055. McCrae, W. M. (1963). Diabetes mellitus following mumps. Lancet, 1, 1300.

Maris, E. P., Enders, J. F., Stokes, J., Jr., and Kane, L. W. (1946). Immunity in mumps: IV. the correlation of the presence of complement-fixing antibody and resistance to mumps in human beings. Fournal of Experimental Medicine, 84, 323.

Melin, K., and Ursing, B. (1958). Diabetes mellitus som komplikation till parotitis epidemica. Nordisk Medicin, 60, 1715.

J. Messaritakis, C. Karabula, C. Kattamis, and N. Matsaniotis

The Paediatric Clinic of Athens University, 'St. Sophie's' Children's Hospital, Goudi 608, Athens, Greece.

\section{Diphenoxylate Hydrochloride ('Lomotil') Poisoning in Children}

Three cases of diphenoxylate hydrochloride (Lomotil) poisoning in children have been reported (Harries and Rossiter, 1969; Henderson and Psaila, 1969; Riley, 1969). We describe a fourth case, to emphasize the great importance of early diagnosis and prompt therapy.

\section{Case Report}

A 2-year-old girl was admitted to hospital in April 1970 at 12.30 p.m. Her parents had brought her directly to hospital because at 11 a.m. on the same day she had been found playing with a bottle of diphenoxylate (Lomotil) tablets (each containing $2.5 \mathrm{mg}$ diphenoxylate hydrochloride and $0.025 \mathrm{mg}$ atropine sulphate). These had been prescribed for her father's 'nervous diarrhoea' and 35 to 40 tablets could not be accounted for. It was feared that this healthy 2-year-old had ingested the missing tablets between 10.30 a.m. and 11 a.m. on the day of admission.

Gastric lavage was performed at 12.30 p.m. No tablets were found in the gastric aspirate, but the child was admitted for observation. She was drowsy and the respiration rate was $12 / \mathrm{min}$.

Respiration rate was recorded half-hourly and remained steady around $20 / \mathrm{min}$ until 8.30 p.m. when she stopped breathing completely. The heart rate and pupillary reactions were normal. Intermittent positive pressure with oxygen via an 'Ambu' bag was applied, and $2 \mathrm{mg}$ nalorphine hydrobromide was injected intramuscularly. Two minutes later spontaneous respirations began, at first gasping in type, but within a further 10 minutes they became deep and regular at a rate of $10 / \mathrm{min}$. The child remained drowsy but responsive to painful stimuli. She showed no neurological deficit. The heart rate and rhythm were normal.

After this episode, the respiration rate was continuously monitored and a second period of apnoea occurred at 3.30 a.m., more than 16 hours after the ingestion of the tablets. Oxygen was given as above for 5 minutes and a further $2 \mathrm{mg}$ nalorphine hydrobromide was injected intramuscularly. This was followed in 2 minutes by the onset of spontaneous respiration.
The patient remained drowsy for 24 hours. The 2 $\mathrm{mg}$ injections of nalorphine were repeated every 4 hours for a full 24 hours, followed by $1 \mathrm{mg}$ every 4 hours for a further 24 hours, when the drug was discontinued. The child remained fully conscious and her respiration gave no cause for further alarm. Chest $x$-ray was normal. She was allowed home perfectly well, 4 days after admission.

\section{Comment}

Diphenoxylate hydrochloride is a widely used drug and is often prescribed for relatively trivial and self-limiting conditions. We do not feel that the dangers of accidental poisoning with this drug are sufficiently well recognized. Diphenoxylate hydrochloride is structurally related to pethidine, is a powerful antitussive, and prolongs the transit time of the intestinal contents. The onset of action is slower and its duration longer than that of morphine, pethidine, or other opiates. The manufacturers of Lomotil ${ }^{\star}$ deliberately added subtherapeutic doses of atropine sulphate to diphenoxylate in order to discourage excessive self medication, but it is very difficult to legislate for the inquisitive and ubiquitous toddler. Significantly all 4 cases so far recorded were 2-year-olds: none showed signs of atropine poisoning.

The patient we describe shows clearly the slow absorption and long duration of action of diphenoxylate hydrochloride, in that the first apnoeic attack developed 10 hours after ingestion and the second one 7 hours later. Henderson and Psaila's patient had ingested only 6 tablets, but the diagnosis was not suspected until 10 hours later. Similar lapses in time between ingestion and symptoms occurred in the cases described by Harries and Rossiter and by Riley. All 3 children were more seriously poisoned than our patient in whom the diagnosis was suspected much earlier. Though the number of tablets actually swallowed was approximate only, and the gastric aspirate contained no visible tablets, it seems likely that prompt gastric lavage played some part in our patient's survival and recovery.

The antitussive action of diphenoxylate hydrochloride may have been partly responsible for the pneumonia which developed in Henderson and Psaila's patient, but the cardinal sign of poisoning in all the cases described was respiratory depression with apnoea. Our patient had two apnoeic attacks only, but the 3 others described were much more seriously affected, e.g. Harries and Rossiter's patient died of irreversible CNS damage after cardiac and respiratory arrests with hypothermia, Riley's patient was not fully conscious for 3 days

^G. D. Searle \& Co. 
before recovery, and Henderson and Psaila's patient was moribund until nalorphine was given.

The use of nalorphine is vital in all cases of diphenoxylate hydrochloride poisoning. It undoubtedly saved the lives of our patient and of Henderson and Psaila's, and there can be fewer more dramatic drug responses in the field of clinical pharmacology. There are no clear rules about dosage, timing, and duration of nalorphine administration, but this drug must be given if respirations become abnormal in a suspected case of diphenoxylate poisoning and repeated frequently if necessary. Some caution is advised because nalorphine itself can cause respiratory depression in normal patients. The average dose is from $0.25 \mathrm{mg}$ for the newborn to $10 \mathrm{mg}$ for the adult.

The manufacturers of 'Lomotil' mention in their reference manual the dangers of narcosis and respiratory depression in accidental overdosage, particularly in children. The case reported above and the 3 others in the literature underline this advice. We stress the importance of emptying the stomach as soon as possible, hospital admission, continuous observation of the patient for at least 48 hours, and the prompt and repeated administration of nalorphine if respiration is threatened.

\section{Summary}

A 2-year-old child swallowed an unknown quantity of diphenoxylate hydrochloride (Lomotil) tablets. Many hours later she developed severe respiratory depression which responded to nalorphine. The dangers of this poisoning in children and its appropriate therapy are discussed.

\section{REFERENCES}

Harries, J. T., and Rossiter, M. (1969). Fatal 'Lomotil' poisoning. Lancet, 1, 150.

Henderson, W., and Psaila, A. (1969). Lomotil poisoning. Lancet, $1,307$.

Riley, I. D. (1969). Lomotil poisoning. Lancet, 1, 373.

We wish to thank Dr. R. R. Gordon for permission to publish this report and Dr. G. R. Venning (Medical Director, Searle and Co. Ltd.) for product information.

\section{R. WheEldon and H. J. HeggarTy}

Paediatric Department, Northern General Hospital, Sheffield.

Correspondence to Dr. R. Wheeldon, Children's Hospital, Western Bank, Sheffield S10 2TH.

\section{Hyperglycaemia Due to Phenytoin Toxicity}

Neurotoxicity due to phenytoin overdosage is well recognized but it has also been reported to cause hyperglycaemia. We report a case of a child presenting with neurotoxicity found to have temporary hyperglycaemia and an abnormal glucose tolerance test with raised insulin levels.

\section{Case Report}

An 11-year-old boy with post-traumatic epilepsy was admitted to a paediatric ward with a history of ataxia, headache, vomiting, and drowsiness. 2 weeks before admission he first had difficulty in walking. His ataxia worsened and about a week later he began to have severe headaches and vomiting. He became increasingly drowsy and admission was requested when he was found to be unrousable. He had a 3-year history of grand mal convulsions after a skull fracture. He had last been seen in the neurological outpatients department 3 weeks previously. Because of increasingly frequent fits his dose of phenytoin was increased from 200 to 300 $\mathrm{mg}$ daily. Primidone $250 \mathrm{mg}$ daily and nitrazepam $5 \mathrm{mg}$ at night were continued as before. There was no evidence that these drugs were not taken as prescribed.

On admission he was stuporose but rousable and had a normal temperature. The only abnormal findings on examination were in the nervous system. His speech was slurred and he was ataxic with tremor and marked nystagmus. Tone and reflexes were variable but showed no localizing features. The clinical picture was suggestive of phenytoin overdosage.

Plasma anticonvulsant levels were estimated by gas chromatography and found to be: Dhenobarbitone $0.3 \mathrm{mg} / 100 \mathrm{ml}$; primidone $0.2 \mathrm{mg} / 100 \mathrm{ml}$; phenytoin $4.4 \mathrm{mg} / 100 \mathrm{ml}$. The therapeutic level of phenytoin is stated to be between 1.0 and $2.0 \mathrm{mg} / 100 \mathrm{ml}$ in the plasma (Kutt and McDowell, 1965).

Glycosuria was noted and plasma glucose estimated as $280 \mathrm{mg} / 100 \mathrm{ml}$. A glucose tolerance test showed a diabetic curve (Fig. 1) with plasma rising from a fasting level of $72 \mathrm{mg} / 100 \mathrm{ml}$ to $214 \mathrm{mg} / 100 \mathrm{ml}$ at $1 \frac{1}{2}$ and 2 hours and only falling to $190 \mathrm{mg} / 100 \mathrm{ml}$ at $2 \frac{1}{2}$ hours. Insulin levels were estimated (Fig. 1) and were found to be raised.

Phenytoin was discontinued and the level was $2 \cdot 2$ $\mathrm{mg} / 100 \mathrm{ml}$ in the plasma at 5 days and undetectable at 10 days. The neurological signs returned to normal over 3 days and he remained free from convulsions taking primidone $250 \mathrm{mg}$ daily.

A repeat glucose tolerance test was normal one month later (Fig. 2), with a fasting level of $84 \mathrm{mg} / 100 \mathrm{ml}$ rising to a maximum of $170 \mathrm{mg} / 100 \mathrm{ml}$ at 1 hour and falling to $56 \mathrm{mg} / 100 \mathrm{ml}$ at $2 \frac{1}{2}$ hours.

\section{Comment}

Phenytoin was first found to produce hyperglycaemia during studies on the effect of electroshock seizures on blood sugars in rabbits (Belton, Etheridge, and Millichap, 1965). An average rise of $130 \mathrm{mg} / 100 \mathrm{ml}$ was noted in animals pretreated with phenytoin, while control animals, given no anticonvulsant, had an average post-shock rise of 